\title{
The Vibration Spectrum of Two Euler-Bernoulli Beams Coupled Via a Dissipative Joint
}

\author{
Chris Abriola \\ Matt Coleman \\ Fairfield University, mcoleman@fairfield.edu \\ Aglika Darakchieva \\ Tyler Wales
}

Follow this and additional works at: https://digitalcommons.fairfield.edu/mathandcomputersciencefacultypubs

Copyright 2017 MSP (Mathematical Science Publishers)

First published in Involve in Vol. 10 (2017), No. 3, published by Mathematical Sciences

Publishers.

The final publisher PDF has been archived here with permission from the copyright holder.

\section{Peer Reviewed}

\section{Repository Citation}

Abriola, Chris; Coleman, Matt; Darakchieva, Aglika; and Wales, Tyler, "The Vibration Spectrum of Two Euler-Bernoulli Beams Coupled Via a Dissipative Joint" (2017). Mathematics Faculty Publications. 50. https://digitalcommons.fairfield.edu/mathandcomputerscience-facultypubs/50

\section{Published Citation}

Abriola, C., Coleman, M. P., Darakchieva, A., \& Wales, T. (2017). The vibration spectrum of two Euler-Bernoulli beams coupled via a dissipative joint. Involve, 10(3), 443-463. doi: 10.2140/involve.2017.10.443.

This Article is brought to you for free and open access by the Mathematics Department at DigitalCommons@Fairfield. It has been accepted for inclusion in Mathematics Faculty Publications by an authorized administrator of DigitalCommons@Fairfield. For more information, please contact digitalcommons@fairfield.edu. 


\section{0
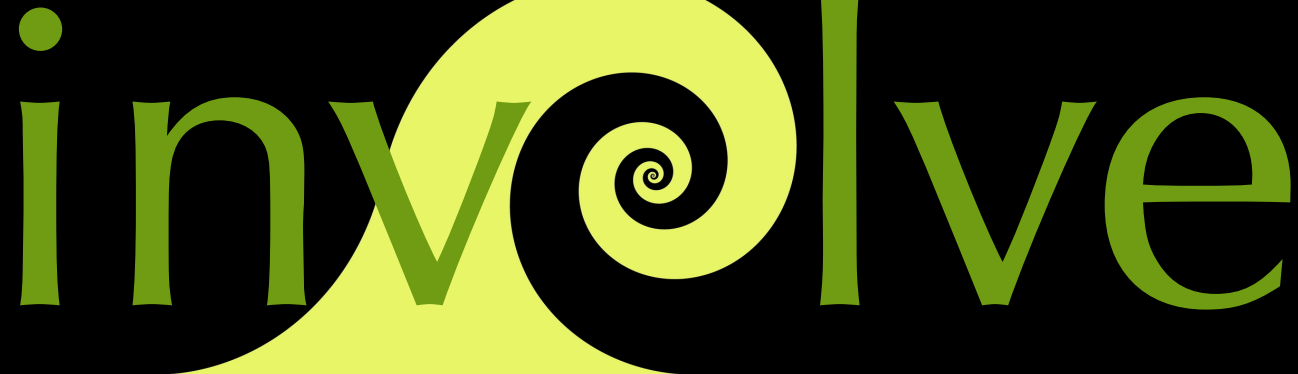 \\ a journal of mathematics}

The vibration spectrum of

two Euler-Bernoulli beams

coupled via a dissipative joint

Chris Abriola, Matthew P. Coleman, Aglika Darakchieva and Tyler Wales 



\title{
The vibration spectrum of two Euler-Bernoulli beams coupled via a dissipative joint
}

\author{
Chris Abriola, Matthew P. Coleman, Aglika Darakchieva and Tyler Wales \\ (Communicated by Kenneth S. Berenhaut)
}

\begin{abstract}
The asymptotic estimation of the vibration spectrum for a system of two identical Euler-Bernoulli beams coupled via each of the four standard types of linear dissipative joint has been solved for the case when one beam is clamped and the other beam is free at the outer ends. Here, we generalize those results and solve the problem for all 40 combinations of energy-conserving end conditions. We provide both asymptotic and numerical results, and we compare the various systems with an eye toward determining which configurations lead to asymptotically equivalent vibration spectra.
\end{abstract}

\section{Introduction}

The design of large or complex structures - bridges, airplanes, robots, buildings, machinery, etc. - entails the joining or coupling of smaller, simpler components, which often can be modeled as beams, plates, or shells. These couplings may include active or passive damping mechanisms for the damping of unwanted vibrations. Successful design requires a knowledge of the system's vibration spectrum, i.e., the set of its natural frequencies of vibration.

There are four standard linear models for describing the vibration of beams the Euler-Bernoulli, Rayleigh, shear, and Timoshenko beams. Of these, the EulerBernoulli is the simplest, with each of the others incorporating one or more physical effects neglected by the Euler-Bernoulli model. Despite the better accuracy of these latter models, the Euler-Bernoulli is accurate enough to be the model of choice for a multitude of physical applications. In addition, the most commonly utilized models for plates and shells are those based on the same assumptions as those governing the Euler-Bernoulli beam. Indeed, given its simplicity and applicability, the Euler-Bernoulli beam may be thought of as the most universal element in structural dynamics.

MSC2010: 74H10, 74H15.

Keywords: vibration, eigenfrequency, Euler-Bernoulli beam, dissipative. 
In this paper, we consider the vibration of a system consisting of two identical Euler-Bernoulli beams, coupled end to end by each of four standard types of dissipative joint, and satisfying any of the standard energy-conserving boundary conditions at each end. Our intent is to estimate and classify the vibration spectrum for all 40 possible configurations (four joint conditions and ten sets of end conditions.)

The problem of serially connected Euler-Bernoulli beams seems first to have been treated in [Chen et al. 1987], while the specific problem here was solved in [Chen et al. 1989] for the case involving a so-called type I joint with clamped-free end conditions. The authors employ an asymptotic method in order to compute the spectrum analytically, and provide numerical results for comparison. In addition, they provide physical models for the four joint types (three being special cases, involving only some of the damping parameters), and present some early experimental results. In [Chen et al. 1988], the authors provide more experimental results and, after smoothing this data, show good agreement with the results from [Chen et al. 1989].

Krantz and Paulsen [1991] generalize to a great extent the asymptotic results in [Chen et al. 1989]. They again treat the case with clamped-free end conditions, but they consider all four types of joints. In addition, they allow for an arbitrary number of beams of arbitrary length! Finally, in [Chen and Zhou 1990], an alternate solution of the problem in [Chen et al. 1989] is provided, using the elegant asymptotic wave propagation method (WPM) of Keller and Rubinow [1960].

In this paper, we consider the case of two identical Euler-Bernoulli beams subject to any of the four types of joint conditions, as given in [Chen et al. 1989], and we generalize by considering all possible combinations of energy-conserving end conditions. We employ WPM in order to derive analytic/asymptotic results, and the Legendre-Tau spectral method for numerical comparisons. These are the first numerical results that we know of for Euler-Bernoulli systems with types II, III and IV joints, and the first asymptotic results for systems without clamped-free end conditions. The asymptotic results allow us easily to compare the vibration spectra for all 40 configurations, permitting us to categorize them, in order to see which configurations may be equivalent insofar as they lead to identical vibration spectra.

This paper is organized as follows: In Section 2, we present the problem and, in Section 3, it is recast in dimensionless form; WPM is applied and the asymptotic results are presented in Section 4, with a brief discussion of the results in Section 5. In Section 6, the numerical results and comparisons are presented.

\section{The problem}

As mentioned, we consider the problem of two identical Euler-Bernoulli beams, connected by any of the four standard dissipative joints, as presented in [Chen et al. 1989]. We have, then, an Euler-Bernoulli beam equation satisfied along each beam: 


$$
\begin{aligned}
& m w_{1 t t}+E I w_{1 x x x x}=0, \quad-L<x<0, t>0, \\
& m w_{2 t t}+E I w_{2 x x x x}=0, \quad 0<x<L, t>0 .
\end{aligned}
$$

Here, $w_{j}(x, t), j=1,2$, is the transverse displacement along beam $j, E$ is the constant Young's modulus, $I$ is the constant (vertical) moment of inertia, and $m$ is the constant linear mass density.

In addition, we have the joint conditions:

Type I:

$$
\begin{aligned}
M_{2}(0, t) & =M_{1}(0, t), \\
V_{2}(0, t) & =V_{1}(0, t), \\
w_{2 t}(0, t)-w_{1 t}(0, t) & =k_{1}^{2} V_{1}(0, t)+c_{1} M_{1}(0, t), \\
w_{2 x t}(0, t)-w_{1 x t}(0, t) & =c_{2} V_{1}(0, t)-k_{2}^{2} M_{1}(0, t) ;
\end{aligned}
$$

Type II:

$$
\begin{aligned}
w_{2}(0, t) & =w_{1}(0, t), \\
M_{2}(0, t) & =M_{1}(0, t), \\
V_{2}(0, t)-V_{1}(0, t) & =k_{1}^{2} w_{1 x}(0, t)+c_{1} M_{1}(0, t), \\
w_{2 x t}(0, t)-w_{1 x t}(0, t) & =c_{2} w_{1 t}(0, t)-k_{2}^{2} M_{1}(0, t) ;
\end{aligned}
$$

Type III:

$$
\begin{aligned}
w_{2}(0, t) & =w_{1}(0, t), \\
w_{2 x}(0, t) & =w_{1 x}(0, t), \\
V_{2}(0, t)-V_{1}(0, t) & =k_{1}^{2} w_{1 t}(0, t)+c_{1} w_{1 x t}(0, t), \\
M_{2}(0, t)-M_{1}(0, t) & =c_{2} w_{1 t}(0, t)-k_{2}^{2} w_{1 x t}(0, t) ;
\end{aligned}
$$

Type IV:

$$
\begin{aligned}
w_{2 x}(0, t) & =w_{1 x}(0, t), \\
V_{2}(0, t) & =V_{1}(0, t), \\
w_{2 t}(0, t)-w_{1 t}(0, t) & =k_{1}^{2} V_{1}(0, t)+c_{1} w_{1 x t}(0, t), \\
M_{2}(0, t)-M_{1}(0, t) & =c_{2} V_{1}(0, t)-k_{2}^{2} w_{1 x t}(0, t) ;
\end{aligned}
$$

where $M_{j}(x, t)$ is the bending moment, and $V_{j}(x, t)$ the shear force, along beam $j$. The damping constants $k_{1}^{2}, k_{2}^{2}, c_{1}$ and $c_{2}$ ensure dissipation of energy so long as

$$
k_{1}^{2}+k_{2}^{2}>0 \quad \text { and } \quad k_{1}^{2} \alpha^{2}+k_{2}^{2} \beta^{2}+\left(c_{1}-c_{2}\right) \alpha \beta>0 \quad \forall \alpha, \beta \in \mathbb{R}
$$

[Chen and Zhou 1990]. For the sake of convenience, we assume throughout the paper that $k_{1} \neq 0$ (corresponding to "type a" joints in [Krantz and Paulsen 1991]) and that $k_{1}^{2} k_{2}^{2}+c_{1} c_{2}>0$. (It is easy to show that $k_{1}^{2} k_{2}^{2}+c_{1} c_{2} \geq 0$, with equality if and only if $c_{1}=-c_{2}= \pm k_{1} k_{2}$.) 
Finally, at the left end of the first beam, we have one of the energy-conserving boundary conditions

$$
\begin{aligned}
\text { clamped }(\mathrm{C}): & w_{1}(-L, t)=w_{1 x}(-L, t)=0, \\
\text { simply supported }(\mathrm{S}): & w_{1}(-L, t)=w_{1 x x}(-L, t)=0, \\
\text { roller supported }(\mathrm{R}): & w_{1 x}(-L, t)=w_{1 x x x}(-L, t)=0, \\
\text { free }(\mathrm{F}): & w_{1 x x}(-L, t)=w_{1 x x x}(-L, t)=0,
\end{aligned}
$$

and similarly at the right end of the second beam. Thus, we have the following ten combinations of boundary conditions to consider:

\section{C-C， C-S， C-R， C-F， S-S， S-R， S-F， R-R， R-F， F-F.}

We note here that, in order for a joint to exist, at least one of the variables $w$ (or $w_{t}$ ), $w_{x}$ (or $w_{x t}$ ), $M$ or $V$ must be discontinuous. In addition, at most one of each pair of conjugate variables ( $w$ and $V, w_{x}$ and $M$ ) can be discontinuous. Thus, types I-IV do, indeed, represent the most general situation for linear joints [Pilkey 1969].

\section{Dimensionless form}

We first separate variables,

$$
w_{j}(x, t)=e^{-i \xi^{2} t} v_{j}(x), \quad j=1,2,
$$

and introduce the new variables

$$
y=\frac{x}{L}, \quad u_{j}(y)=\frac{v_{j}(x)}{L}, \quad j=1,2 .
$$

Also, in order to apply WPM, we let $y \rightarrow-y$ along the second beam, as it is convenient to have both beams on the same $y$-interval. The resulting dimensionless ODEs are

$$
u_{j}^{(4)}(y)-k^{4} u_{j}(y)=0, \quad-1<y<0, \quad j=1,2,
$$

where

$$
k^{2}=\sqrt{\frac{m}{E I}} L^{2} \xi^{2} .
$$

The new joint conditions are:

Type I:

$$
\begin{gathered}
u_{2}^{\prime \prime}(0)-u_{1}^{\prime \prime}(0)=0, \\
u_{2}^{\prime \prime \prime}(0)+u_{1}^{\prime \prime \prime}(0)=0, \\
i k^{2}\left[u_{2}(0)-u_{1}(0)\right]-p_{11} u_{1}^{\prime \prime \prime}(0)-q_{11} u_{1}^{\prime \prime}(0)=0, \\
i k^{2}\left[u_{2}^{\prime}(0)+u_{2}^{\prime}(0)\right]-p_{12} u_{1}^{\prime \prime}(0)+q_{12} u_{1}^{\prime \prime \prime}(0)=0 ;
\end{gathered}
$$


Type II:

$$
\begin{gathered}
u_{2}(0)-u_{1}(0)=0, \\
u_{2}^{\prime \prime}(0)-u_{1}^{\prime \prime}(0)=0, \\
u_{2}^{\prime \prime \prime}(0)+u_{1}^{\prime \prime \prime}(0)+i k^{2} p_{21} u_{1}(0)+q_{21} u_{1}^{\prime \prime}(0)=0, \\
i k^{2}\left[u_{2}^{\prime}(0)+u_{1}^{\prime}(0)\right]-p_{22} u_{1}^{\prime \prime}(0)+i k^{2} q_{22} u_{1}(0)=0 ;
\end{gathered}
$$

Type III:

$$
\begin{gathered}
u_{2}(0)-u_{1}(0)=0, \\
u_{2}^{\prime}(0)+u_{1}^{\prime}(0)=0, \\
u_{2}^{\prime \prime}(0)-u_{1}^{\prime \prime}(0)+i k^{2} p_{31} u_{1}^{\prime}(0)-i k^{2} q_{31} u_{1}(0)=0, \\
u_{2}^{\prime \prime \prime}(0)+u_{1}^{\prime \prime \prime}(0)+i k^{2} p_{32} u_{1}(0)+i k^{2} q_{32} u_{1}^{\prime}(0)=0 ;
\end{gathered}
$$

Type IV:

$$
\begin{gathered}
u_{2}^{\prime}(0)+u_{1}^{\prime}(0)=0, \\
u_{2}^{\prime \prime \prime}(0)+u_{1}^{\prime \prime \prime}(0)=0, \\
i k^{2}\left[u_{2}(0)-u_{1}(0)\right]-p_{41} u_{1}^{\prime \prime \prime}(0)-i k^{2} q_{41} u_{1}^{\prime}(0)=0, \\
u_{2}^{\prime \prime}(0)-u_{1}^{\prime \prime}(0)+i k^{2} p_{42} u_{1}^{\prime}(0)-q_{42} u_{1}(0)=0 .
\end{gathered}
$$

Here, the constants $p_{i j}$ and $q_{i j}$, where $i=1,2,3,4, j=1,2$, are given by:

Type I:

$$
p_{11}=\frac{k_{1}^{2} \sqrt{m E I}}{L}, \quad p_{12}=k_{2}^{2} L \sqrt{m E I}, \quad q_{11}=c_{1} \sqrt{m E I}, \quad q_{12}=c_{2} \sqrt{m E I} ;
$$

Type II:

$$
p_{21}=\frac{k_{1}^{2} L}{\sqrt{m E I}}, \quad p_{22}=k_{2}^{2} L \sqrt{m E I}, \quad q_{21}=c_{1} L, \quad q_{22}=c_{2} L ;
$$

Type III:

$$
p_{31}=\frac{k_{1}^{2}}{L \sqrt{m E I}}, \quad p_{32}=\frac{k_{2}^{2} L}{\sqrt{m E I}}, \quad q_{31}=\frac{c_{1}}{\sqrt{m E I}}, \quad q_{32}=\frac{c_{2}}{\sqrt{m E I}} ;
$$

Type IV:

$$
p_{41}=\frac{k_{1}^{2} \sqrt{m E I}}{L}, \quad p_{42}=\frac{k_{2}^{2}}{L \sqrt{m E I}}, \quad q_{41}=\frac{c_{1}}{L}, \quad q_{42}=\frac{c_{2}}{L} .
$$

Note that $k_{1}^{2} \alpha^{2}+k_{2}^{2} \beta^{2}+\left(c_{1}-c_{2}\right) \alpha \beta \geq 0$ if and only if

$$
p_{j 1} \alpha^{2}+p_{j 2} \beta^{2}+\left(q_{j 1}-q_{j 2}\right) \alpha \beta \geq 0, \quad j=1,2,3,4 .
$$


For $j=1,2$, the new boundary conditions are

$$
\begin{aligned}
& \mathrm{C}: u_{j}(-1)=u_{j}^{\prime}(-1)=0, \\
& \mathrm{~S}: u_{j}(-1)=u_{j}^{\prime \prime}(-1)=0, \\
& \mathrm{R}: u_{j}^{\prime}(-1)=u_{j}^{\prime \prime \prime}(-1)=0, \\
& \mathrm{~F}: u_{j}^{\prime \prime}(-1)=u_{j}^{\prime \prime \prime}(-1)=0 .
\end{aligned}
$$

\section{Asymptotic estimation of vibration frequencies by WPM}

Applying WPM to the problem is identical to writing the general solutions of the ODEs (1) as

$$
\begin{aligned}
u(x)=\left[\begin{array}{l}
u_{1}(x) \\
u_{2}(x)
\end{array}\right] & =\left[\begin{array}{l}
A_{1} \\
A_{2}
\end{array}\right] e^{i k x}+\left[\begin{array}{l}
B_{1} \\
B_{2}
\end{array}\right] e^{-i k x}+\left[\begin{array}{l}
C_{1} \\
C_{2}
\end{array}\right] e^{k x}+\left[\begin{array}{l}
D_{1} \\
D_{2}
\end{array}\right] e^{-k(x+1)} \\
& =\left[\begin{array}{l}
A_{3} \\
A_{4}
\end{array}\right] e^{i k(x+1)}+\left[\begin{array}{l}
B_{3} \\
B_{4}
\end{array}\right] e^{-i k(x+1)}+\left[\begin{array}{l}
C_{1} \\
C_{2}
\end{array}\right] e^{k x}+\left[\begin{array}{l}
D_{1} \\
D_{2}
\end{array}\right] e^{-k(x+1)},
\end{aligned}
$$

applying the joint conditions to the first expression in (2) and the boundary conditions to the second expression in (2). Here, we follow Chen and Zhou [1990] and stipulate that $\operatorname{Re}(k) \geq 0$ (else, we just replace $k$ by $-k$ ). Applying the boundary conditions, neglecting the terms of $O\left(e^{-k}\right)$, and eliminating $D_{1}$ and $D_{2}$ leads to

$$
\left[\begin{array}{l}
A_{3} \\
A_{4}
\end{array}\right]=\left[\begin{array}{ll}
a & 0 \\
0 & b
\end{array}\right]\left[\begin{array}{l}
B_{3} \\
B_{4}
\end{array}\right]=R_{2}\left[\begin{array}{l}
B_{3} \\
B_{4}
\end{array}\right] .
$$

Here, $a$ and $b$ depend on the boundary conditions, as follows:

$$
a=b=i: \mathrm{C}-\mathrm{C}, \mathrm{C}-\mathrm{F}, \mathrm{F}-\mathrm{F},
$$

$$
a=b=1: \mathrm{R}-\mathrm{R}, \quad a=b=-1: \mathrm{S}-\mathrm{S}, \quad a=-1, b=1: \mathrm{S}-\mathrm{R},
$$

$a=i, b=1: \mathrm{C}-\mathrm{R}, \quad a=i, b=-1: \mathrm{C}-\mathrm{S}, \quad a=1, b=i: \mathrm{R}-\mathrm{F}, \quad a=-1, b=i: \mathrm{S}-\mathrm{F}$,

where, e.g., C-F signifies that the first beam is clamped at the left end and the second beam is free at the right end.

Next, we apply the joint conditions, again neglecting terms of $O\left(e^{-k}\right)$, and eliminate $C_{1}$ and $C_{2}$. The result is a relationship of the form

$$
M_{1}(k)\left[\begin{array}{l}
B_{1} \\
B_{2}
\end{array}\right]=M_{2}(k)\left[\begin{array}{l}
A_{1} \\
A_{2}
\end{array}\right],
$$

where each matrix $M_{j}$ is $2 \times 2$. Solving for $\left[\begin{array}{l}B_{1} \\ B_{2}\end{array}\right]$, we have

$$
\left[\begin{array}{l}
B_{1} \\
B_{2}
\end{array}\right]=M_{1}^{-1}(k) M_{2}(k)\left[\begin{array}{l}
A_{1} \\
A_{2}
\end{array}\right]=R_{1}(k)\left[\begin{array}{l}
A_{1} \\
A_{2}
\end{array}\right],
$$


for which we find it more convenient to write

$$
\left[\begin{array}{l}
B_{1} \\
B_{2}
\end{array}\right]=\frac{1}{\operatorname{det} M_{1}(k)} R_{1}^{\prime}(k)\left[\begin{array}{l}
A_{1} \\
A_{2}
\end{array}\right] .
$$

For the sake of completeness, we provide $R_{1}^{\prime}$ and det $M_{1}$ for each of the four joints:

Type I:

$$
\begin{gathered}
\operatorname{det} M_{1}=2(1+i) p_{11} k^{2}+i\left(p_{11} p_{12}+q_{11} q_{12}+8\right) k+2(-1+i) p_{12}=t_{11}, \\
R_{1}^{\prime}=\left[\begin{array}{ll}
u+v & w+z \\
w-z & u-v
\end{array}\right]=T_{11},
\end{gathered}
$$

where

$$
\begin{array}{ll}
u=2 i p_{11} k^{2}-\left(p_{11} p_{12}+q_{11} q_{12}\right) k-2 i p_{12}, & v=2\left(q_{11}-q_{12}\right) k, \\
w=2 p_{11} k^{2}+8 i k-2 p_{12}, & z=2\left(q_{11}+q_{12}\right) k .
\end{array}
$$

Type II:

$$
\begin{gathered}
\operatorname{det} M_{1}=8 i k^{2}+2(-1+i)\left(p_{21}+p_{22}+q_{21}+q_{22}\right) k-2\left(p_{21} p_{22}+q_{21} q_{22}\right), \\
R_{1}^{\prime}=\left[\begin{array}{cc}
-v & 2 u \\
2 u & -v
\end{array}\right],
\end{gathered}
$$

where

$$
\begin{aligned}
& u=4 i k^{2}+\left[-\left(p_{21}+p_{22}\right)+i\left(q_{21}+q_{22}\right)\right] k \\
& v=2\left[i\left(p_{21}+p_{22}\right)-\left(q_{21}+q_{22}\right)\right] k-2\left(p_{21} p_{22}+q_{21} q_{22}\right) .
\end{aligned}
$$

Type III:

$$
\begin{gathered}
\operatorname{det} M_{1}=2(1+i) p_{31} k^{2}+i\left(p_{31} p_{32}+q_{31} q_{32}\right) k+2(-1+i) p_{32}=t_{31}, \\
R_{1}^{\prime}=\left[\begin{array}{ll}
u+v & w-z \\
w+z & u-v
\end{array}\right]=T_{31},
\end{gathered}
$$

where

$$
\begin{aligned}
u & =2 i p_{31} k^{2}-\left(p_{31} p_{32}+q_{31} q_{32}\right) k-2 i p_{32}, & v & =-2\left(q_{31}-q_{32}\right) k, \\
w & =2 p_{31} k^{2}+8 i k-p_{32}, & z & =2\left(q_{31}+q_{32}\right) k .
\end{aligned}
$$

Type IV:

$$
\begin{gathered}
\operatorname{det} M_{1}=-2 i\left(p_{41} p_{42}+q_{41} q_{42}\right) k^{2}+2(1-i)\left(p_{41}+p_{42}+q_{41}+q_{42}\right) k+8, \\
R_{1}^{\prime}=\left[\begin{array}{cc}
-u & -2 v \\
-2 v & -u
\end{array}\right],
\end{gathered}
$$

where

$$
\begin{aligned}
& u=2 i\left(p_{41} p_{42}+q_{41} q_{42}\right) k^{2}+2\left[-\left(p_{41}+p_{42}\right)+i\left(q_{41}+q_{42}\right)\right] k, \\
& v=\left[i\left(p_{41}+p_{42}\right)-\left(q_{41}+q_{42}\right)\right] k-4 .
\end{aligned}
$$


Now, we also see from the general solution (2) that

$$
\left[\begin{array}{l}
A_{1} \\
A_{2}
\end{array}\right]=\left[\begin{array}{l}
A_{3} \\
A_{4}
\end{array}\right] e^{i k}, \quad\left[\begin{array}{l}
B_{1} \\
B_{2}
\end{array}\right]=\left[\begin{array}{l}
B_{3} \\
B_{4}
\end{array}\right] e^{-i k} .
$$

Combining (3), (5), and (7) then gives us

$$
\begin{aligned}
{\left[\begin{array}{l}
B_{1} \\
B_{2}
\end{array}\right]=R_{1}(k)\left[\begin{array}{l}
A_{1} \\
A_{2}
\end{array}\right] } & =R_{1}(k) e^{i k}\left[\begin{array}{l}
A_{3} \\
A_{4}
\end{array}\right] \\
& =R_{1}(k) e^{i k} R_{2}\left[\begin{array}{l}
B_{3} \\
B_{4}
\end{array}\right]=R_{1}(k) e^{i k} R_{2} e^{i k}\left[\begin{array}{l}
B_{1} \\
B_{2}
\end{array}\right] .
\end{aligned}
$$

Thus, we are to find those values of $k$ for which

$$
\operatorname{det}\left[e^{2 i k} R_{1}(k) R_{2}-I\right]=0
$$

or

$$
\operatorname{det}\left[R_{1}^{\prime} R_{2}-e^{-2 i k}\left(\operatorname{det} M_{1}(k)\right) I\right]=\operatorname{det}\left[R_{1}^{\prime} R_{2}-\lambda I\right]=0
$$

Thus, we need only compute the eigenvalues of $R_{1}^{\prime}(k) R_{2}$.

It is easy to see that, if we identify $p_{11} \rightarrow p_{31}, p_{12} \rightarrow p_{32}, q_{11} \rightarrow q_{31}, q_{12} \rightarrow q_{32}$, we have $t_{31}=t_{11}$ and $T_{31}=\left(T_{11}\right)^{T}$. Thus, $R_{11}^{\prime} R_{2}$ and $R_{13}^{\prime} R_{2}$ will have the same eigenvalues, and the spectra for the types I and III joints are identical for each $R_{2}$; i.e., given any set of end/boundary conditions, the types I and III joints have identical spectra, asymptotically. This generalizes the result in [Krantz and Paulsen 1991] where they show that these spectra are identical in the case of C-F end conditions.

Continuing the analysis, in each case the matrix $R_{1}^{\prime}(k) R_{2}$ will have two eigenvalues, $\lambda_{1}(k)$ and $\lambda_{2}(k)$. It is easy to show, as in [Chen and Zhou 1990], that these eigenvalues are distinct. It follows that, in each case, there will be two streams or branches of frequencies, satisfying

$$
\lambda_{j}(k)=e^{-2 i k} \operatorname{det} M_{1}(k) \quad \text { or } \quad e^{-2 i k}=\frac{\lambda_{j}(k)}{\operatorname{det} M_{1}(k)}, \quad j=1,2,
$$

where each $\lambda_{j}(k)$ and det $M_{1}(k)$ are quadratic polynomials in $k$. Thus, as (9) is unwieldy, we follow [Chen and Zhou 1990] and we use the first-degree Taylor approximation

$$
\frac{a_{1} k^{2}+b_{1} k+c_{1}}{a_{2} k^{2}+b_{2} k+c_{2}}=\frac{a_{1}}{a_{2}}+\frac{a_{2} b_{1}-a_{1} b_{2}}{a_{2}^{2}} \frac{1}{k}+O\left(\frac{1}{k^{2}}\right) .
$$

Applying (10) to (9) yields an equation of the form

$$
e^{-2 i k}=d_{1}\left(1-d_{2} \frac{1}{k}\right)+O\left(\frac{1}{k^{2}}\right), \quad\left|d_{1}\right|=1,
$$


and, taking the (complex) log of (11) and using the Taylor approximation

$$
\ln \left(1-d_{2} \frac{1}{k}+O\left(\frac{1}{k^{2}}\right)\right)=-d_{2} \frac{1}{k}+O\left(\frac{1}{k^{2}}\right)
$$

we have

$$
-2 i k=-d_{2} \frac{1}{k}+i\left(\arg d_{1}-2 n \pi\right)+O\left(\frac{1}{k^{2}}\right), \quad n=0,1,2, \ldots
$$

We note here that the choice of $-2 n \pi$ is based on our earlier assumption that $\operatorname{Re}(k) \geq 0$. We rewrite (12) as a quadratic equation, realizing that multiplying by $k$ will add an extraneous root of $O(1 / k)$, and after also employing the Taylor approximation

$$
\sqrt{1+\epsilon}=1+\frac{1}{2} \epsilon+O\left(\epsilon^{2}\right)
$$

we arrive at

$$
-i k^{2}=-d_{2}-\left(\frac{1}{2} \arg d_{1}-n \pi\right)^{2} i+O\left(\frac{1}{k}\right)
$$

Here, we provide the expressions for $-i k^{2}$ for all 40 cases:

Type I:

$a=b(\mathrm{C}-\mathrm{C}, \mathrm{C}-\mathrm{F}, \mathrm{F}-\mathrm{F}, \mathrm{S}-\mathrm{S}, \mathrm{R}-\mathrm{R}, \mathrm{F}-\mathrm{F}):$

$$
\begin{aligned}
& -i k^{2}=-\frac{p_{11} p_{12}+q_{11} q_{12}}{2 p_{11}}-\left(\frac{1}{2} \arg a-n \pi\right)^{2} i, \\
& -i k^{2}=-\frac{4}{p_{11}}-\left(\frac{1}{2} \arg (-a)-n \pi\right)^{2} i
\end{aligned}
$$

$$
\begin{aligned}
& \left.\begin{array}{l}
a=-b=-1(\mathrm{~S}-\mathrm{R}): \\
-i k^{2}=-\left(4 p_{11}\right)^{-1}\left[p_{11} p_{12}+q_{11} q_{12}+8-2 \sqrt{2}\left(q_{11}-q_{12}\right) i\right]-\left(\frac{1}{8} \pi-n \pi\right)^{2} i, \\
-i k^{2}=-\left(4 p_{11}\right)^{-1}\left[p_{11} p_{12}+q_{11} q_{12}+8+2 \sqrt{2}\left(q_{11}-q_{12}\right) i\right]-\left(\frac{5}{8} \pi-n \pi\right)^{2} i ; \\
a=1, b=i(\mathrm{R}-\mathrm{F}): \\
-i k^{2}=-\left(4 \sqrt{3} p_{11}\right)^{-1}\left[(\sqrt{3}+1)\left(p_{11} p_{12}+q_{11} q_{12}\right)+4 i\left(q_{11}-q_{12}\right)+8(\sqrt{3}-1)\right] \\
-i k^{2}=-\left(4 \sqrt{3} p_{11}\right)^{-1}\left[(\sqrt{3}-1)\left(p_{11} p_{12}+q_{11} q_{12}\right)-4 i\left(q_{11}-q_{12}\right)+8(\sqrt{3}+1)\right] \\
-\left(\frac{5}{12} \pi-n \pi\right)^{2} i,
\end{array}\right]
\end{aligned}
$$




$$
\begin{aligned}
& \underline{a=-1, b=i(\mathrm{~S}-\mathrm{F})} \\
& -i k^{2}=-\left(4 \sqrt{3} p_{11}\right)^{-1}\left[(\sqrt{3}+1)\left(p_{11} p_{12}+q_{11} q_{12}\right)-4 i\left(q_{11}-q_{12}\right)+8(\sqrt{3}-1)\right] \\
& -\left(\frac{1}{3} \pi-n \pi\right)^{2} i \\
& -i k^{2}=-\left(4 \sqrt{3} p_{11}\right)^{-1}\left[(\sqrt{3}-1)\left(p_{11} p_{12}+q_{11} q_{12}\right)+4 i\left(q_{11}-q_{12}\right)+8(\sqrt{3}+1)\right] \\
& -\left(\frac{2}{3} \pi-n \pi\right)^{2} i \\
& a=i, b=1(\mathrm{C}-\mathrm{R}) \text { : } \\
& -i k^{2}=-\left(4 \sqrt{3} p_{11}\right)^{-1}\left[(\sqrt{3}+1)\left(p_{11} p_{12}+q_{11} q_{12}\right)-4 i\left(q_{11}-q_{12}\right)+8(\sqrt{3}-1)\right] \\
& -\left(\frac{1}{12} \pi-n \pi\right)^{2} i \\
& -i k^{2}=-\left(4 \sqrt{3} p_{11}\right)^{-1}\left[(\sqrt{3}-1)\left(p_{11} p_{12}+q_{11} q_{12}\right)+4 i\left(q_{11}-q_{12}\right)+8(\sqrt{3}+1)\right] \\
& -\left(\frac{5}{12} \pi-n \pi\right)^{2} i \\
& a=i, b=-1(\mathrm{C}-\mathrm{S}) \text { : } \\
& -i k^{2}=-\left(4 \sqrt{3} p_{11}\right)^{-1}\left[(\sqrt{3}+1)\left(p_{11} p_{12}+q_{11} q_{12}\right)+4 i\left(q_{11}-q_{12}\right)+8(\sqrt{3}-1)\right] \\
& -\left(\frac{1}{3} \pi-n \pi\right)^{2} i \\
& -i k^{2}=-\left(4 \sqrt{3} p_{11}\right)^{-1}\left[(\sqrt{3}-1)\left(p_{11} p_{12}+q_{11} q_{12}\right)-4 i\left(q_{11}-q_{12}\right)+8(\sqrt{3}+1)\right] \\
& -\left(\frac{2}{3} \pi-n \pi\right)^{2} i \text {. }
\end{aligned}
$$

Type III: This is the same as type I, with $p_{1 j} \rightarrow p_{3 j}, q_{1 j} \rightarrow q_{3 j}, j=1,2$.

\section{Type II:}

$a=b$ (C-C, C-F, S-S, R-R, F-F):

$$
\begin{gathered}
-i k^{2}=-\frac{1}{2}\left[p_{21}+p_{22}+i\left(q_{21}+q_{22}\right)\right]-\left(\frac{1}{2} \arg a-n \pi\right)^{2} i \\
-i k^{2}=-\left(\frac{1}{2} \arg (-a)-n \pi\right)^{2} i \\
\frac{a=-b=-1(\mathrm{~S}-\mathrm{R}):}{-i k^{2}=-\frac{1}{4}\left[p_{21}+p_{22}+i\left(q_{21}+q_{22}\right)\right]-\left(\frac{1}{4} \pi-n \pi\right)^{2} i} \\
-i k^{2}=-\frac{1}{4}\left[p_{21}+p_{22}+i\left(q_{21}+q_{22}\right)\right]-\left(\frac{3}{4} \pi-n \pi\right)^{2} i \\
\frac{a=i, b=1(\mathrm{C}-\mathrm{R}) ; a=1, b=i(\mathrm{R}-\mathrm{F}):}{-i k^{2}=-\frac{1}{8}(2+\sqrt{2})\left[p_{21}+p_{22}+i\left(q_{21}+q_{22}\right)\right]-\left(\frac{1}{8} \pi-n \pi\right)^{2} i} \\
-i k^{2}=-\frac{1}{8}(2-\sqrt{2})\left[p_{21}+p_{22}+i\left(q_{21}+q_{22}\right)\right]-\left(\frac{5}{8} \pi-n \pi\right)^{2} i
\end{gathered}
$$




$$
\begin{aligned}
& a=i, b=-1(\mathrm{C}-\mathrm{S}) ; a=-1, b=i(\mathrm{~S}-\mathrm{F}): \\
& -i k^{2}=-\frac{1}{8}(2+\sqrt{2})\left[p_{21}+p_{22}+i\left(q_{21}+q_{22}\right)\right]-\left(\frac{3}{8} \pi-n \pi\right)^{2} i, \\
& -i k^{2}=-\frac{1}{8}(2-\sqrt{2})\left[p_{21}+p_{22}+i\left(q_{21}+q_{22}\right)\right]-\left(\frac{7}{8} \pi-n \pi\right)^{2} i .
\end{aligned}
$$

Type IV:

$a=b(\mathrm{C}-\mathrm{C}, \mathrm{C}-\mathrm{F}, \mathrm{S}-\mathrm{S}, \mathrm{R}-\mathrm{R}, \mathrm{F}-\mathrm{F})$ :

$$
\begin{aligned}
& -i k^{2}=-2 \frac{p_{41}+p_{42}+i\left(q_{41}+q_{42}\right)}{p_{41} p_{42}+q_{41} q_{42}}-\left(\frac{1}{2} \arg a-n \pi\right)^{2} i, \\
& -i k^{2}=-\left(\frac{1}{2} \arg a-n \pi\right)^{2} i
\end{aligned}
$$

$a \neq b(\mathrm{C}-\mathrm{S}, \mathrm{C}-\mathrm{R}, \mathrm{S}-\mathrm{R}, \mathrm{S}-\mathrm{F}, \mathrm{R}-\mathrm{F})$ :

$$
\begin{aligned}
& -i k^{2}=-\frac{p_{41}+p_{42}+i\left(q_{41}+q_{42}\right)}{p_{41} p_{42}+q_{41} q_{42}}-\left(\frac{1}{2} \arg a-n \pi\right)^{2} i, \\
& -i k^{2}=-\frac{p_{41}+p_{42}+i\left(q_{41}+q_{42}\right)}{p_{41} p_{42}+q_{41} q_{42}}-\left(\frac{1}{2} \arg b-n \pi\right)^{2} i .
\end{aligned}
$$

\section{Discussion of asymptotic results}

Again, we begin by noting that, for each set of end conditions, the type I and type III joints are asymptotically equivalent. This agrees with what is found in [Krantz and Paulsen 1991] for C-F end conditions.

We see also that, for many choices of the end conditions, the damping rates for the type II and type IV joints are asymptotically equivalent. Specifically, for those cases satisfying $a=b$, there is an asymptotically undamped branch, while, for the other branch, we need only choose our damping constants so that

$$
p_{21}=\frac{4 p_{41}}{p_{41} p_{42}+q_{41} q_{42}}, \quad \text { etc. }
$$

We have a similar equivalence for the case $a=-b=-1$ (S-R).

It is of particular interest that, in so many cases, for each type of joint, a term of the form $q_{j 1}-q_{j 2}$ or $q_{j 1}+q_{j 2}$ appears in $\operatorname{Im}\left(-i k^{2}\right)$. Thus, there are examples where the $q_{j 1}$ and $q_{j 2}$ affect the "frequency part" of the eigenfrequencies. Indeed, a term of this form appears in all cases except for those where there is a type I or type III joint and end conditions satisfying $a=b$. Thus, this behavior would not have been encountered in [Chen and Zhou 1990]. These terms are encountered in [Krantz and Paulsen 1991]; however, they seem to be discarded.

More specifically, in computing the damping rates, [Krantz and Paulsen 1991] arrives at a correct term similar to

$$
p_{j 1}+p_{j 2}+i\left(q_{j 1}+q_{j 2}\right)
$$


and then arrives at the, again correct, damping rate of

$$
-\operatorname{Re}\left[p_{j 1}+p_{j 2}+i\left(q_{j 1}+q_{j 2}\right)\right] .
$$

However, the $i\left(q_{j 1}+q_{j 2}\right)$ part is then dropped from consideration; although, as we shall see below, these efforts do show up in the numerical results. This does, however, seem to be an easy fix for Krantz and Paulsen [1991, p. 399].

\section{Numerical results and comparisons}

We have applied the Legendre-Tau spectral method to the problem. The problem is recast so that each beam has domain $-1 \leq x \leq 1$, after which we approximate $u_{1}$ and $u_{2}$ by

$$
u_{1}(x)=\sum_{n=0}^{N} a_{n} P_{n}(x), \quad u_{2}(x)=\sum_{n=0}^{N} b_{n} P_{n}(x),
$$

where $P_{n}$ is the Legendre polynomial of degree $n$ [Gottlieb and Orszag 1977]. Computations were performed within MATLAB, and also using Fortran 90 on a laptop. Computations at $N=40$ and $N=42$ show that all results in the table below converge to at least five decimal places.

In each table, we present the first 20 eigenfrequencies. We note here that, although we have only negative imaginary parts in our asymptotic results, in fact the conjugate of each eigenfrequency also is an eigenfrequency. In the following example, we list only those with positive imaginary parts.

In our first example, we compare numerical results for a type I and a type III joint, with $\mathrm{C}-\mathrm{F}$ end conditions, for $q_{j 1}=q_{j 2}=0$, and for various values of $p_{11}=p_{31}$ and $p_{12}=p_{32}$. The results appear in Tables 1-3.

The purpose here is threefold - to compare the numerical results for type I and type III joints (remembering that we have shown them to be asymptotically equivalent), to compare the numerical and asymptotic results, of course, and to see what happens when we vary the "dominant" damping parameters, $p_{i j}$.

For Table 1, we have taken $p_{11}=p_{31}=p_{12}=p_{32}=1$. The first thing we must point out is the very close match between the type I and type III numerical results. We shall see similar behavior in the remaining results examining types I and III (Tables 2-4).

We also are surprised to see such a good match between the numerical and asymptotic results at this low end of the spectrum. Indeed, from the second eigenfrequency on, it is clear that the numerical spectrum already has split into the expected two branches or streams.

For Table 2, we have let $p_{11}=p_{31}=2$ and $p_{12}=p_{32}=0.5$. Again, we have a very close match between types I and III, and a close match between the numerical and asymptotic results. 


\begin{tabular}{|lc|lc|cc|}
\hline \multicolumn{2}{|c|}{$\begin{array}{c}\text { type I } \\
\text { numerical }\end{array}$} & \multicolumn{2}{c|}{$\begin{array}{c}\text { type III } \\
\text { numerical }\end{array}$} & \multicolumn{2}{c|}{ WPM } \\
\hline \multicolumn{1}{|c|}{$\operatorname{Re}$} & $\mathrm{Im}$ & \multicolumn{1}{c|}{$\operatorname{Re}$} & $\mathrm{Im}$ & $\mathrm{Re}$ & $\mathrm{Im}$ \\
\hline-0.49507 & 0.77898 & -0.49507 & 0.77898 & & \\
-0.53772 & 5.5070 & -0.53772 & 5.5070 & -0.5 & 5.5517 \\
-3.6704 & 20.562 & -3.6704 & 20.562 & -4.0 & 22.207 \\
-0.49979 & 30.205 & -0.49979 & 30.205 & -0.5 & 30.226 \\
-3.8734 & 60.711 & -3.8734 & 60.711 & -4.0 & 61.685 \\
-0.49981 & 74.625 & -0.49981 & 74.625 & -0.5 & 74.639 \\
-3.9307 & 120.20 & -3.9307 & 120.20 & -4.0 & 120.90 \\
-0.49989 & 138.78 & -0.49989 & 138.78 & -0.5 & 138.79 \\
-3.9561 & 199.31 & -3.9561 & 199.31 & -4.0 & 199.86 \\
-0.49992 & 222.67 & -0.49992 & 222.67 & -0.5 & 222.68 \\
-3.9697 & 298.10 & -3.9697 & 298.10 & -4.0 & 298.56 \\
-0.49995 & 326.31 & -0.49995 & 326.31 & -0.5 & 326.31 \\
-3.9778 & 416.61 & -3.9777 & 416.61 & -4.0 & 416.99 \\
-0.49996 & 449.68 & -0.49997 & 449.68 & -0.5 & 449.68 \\
-3.9830 & 554.83 & -3.9829 & 554.83 & -4.0 & 555.17 \\
-0.49997 & 592.79 & -0.49999 & 592.79 & -0.5 & 592.79 \\
-3.9866 & 712.79 & -3.9866 & 712.79 & -4.0 & 713.08 \\
-0.49997 & 755.64 & -0.49987 & 755.64 & -0.5 & 755.64 \\
-3.9889 & 890.47 & -3.9901 & 890.47 & -4.0 & 890.73 \\
-0.50000 & 938.22 & -4.9987 & 938.22 & -0.5 & 938.23 \\
\hline
\end{tabular}

Table 1. Types I and III joints, C-F end conditions, with $p_{11}=$ $p_{12}=1, q_{11}=q_{12}=0$.

For Table 3, we have $p_{11}=p_{31}=0.5$ and $p_{12}=p_{32}=2$. Here, once more, the match for types I and III is very close. Meanwhile, the convergence of the numerical to the asymptotic results is somewhat slower than in the previous two tables, especially for the branch with real part equaling -8 . Indeed, this slower but smooth convergence is seen quite clearly in Figure 1, where we have plotted the data from Table 3.

For Table 4, we continue to consider types I and III joints and C-F end conditions, with $p_{11}=p_{31}=p_{12}=p_{32}=1$ but with $q_{11}=q_{31}=0.5$ and $q_{12}=q_{32}=0.7$. Once again, the types I and III results are an excellent match. In addition, the smooth convergence of the numerical to the asymptotic results is similar to that in the previous example, and can be seen clearly in Figure 2.

Given the excellent agreement between the type I and type III numerical results, we are curious as to "how equivalent" they actually are. We have tried to compare the determinant equations for the exact solutions, but so far we have had no luck. 


\begin{tabular}{|c|c|c|c|c|c|}
\hline \multicolumn{2}{|c|}{$\begin{array}{c}\text { type I } \\
\text { numerical }\end{array}$} & \multicolumn{2}{|c|}{$\begin{array}{c}\text { type III } \\
\text { numerical }\end{array}$} & \multicolumn{2}{|c|}{ WPM } \\
\hline $\mathrm{Re}$ & Im & $\mathrm{Re}$ & Im & $\operatorname{Re}$ & $\mathrm{Im}$ \\
\hline-1.7301 & 1.1041 & -1.7300 & 1.1041 & & \\
\hline-0.28489 & 5.5602 & -0.28489 & 5.5602 & -0.25 & 5.5517 \\
\hline-1.9703 & 21.818 & -1.9702 & 21.818 & -2.0 & 22.207 \\
\hline-0.25005 & 30.221 & -0.25005 & 30.220 & -0.25 & 30.226 \\
\hline-1.9856 & 61.556 & -1.9856 & 61.445 & -2.0 & 61.685 \\
\hline-0.24998 & 75.635 & -0.24998 & 74.635 & -0.25 & 74.639 \\
\hline-1.9917 & 120.73 & -1.9917 & 120.72 & -2.0 & 120.90 \\
\hline-0.24999 & 138.79 & -0.24999 & 138.79 & -0.25 & 138.79 \\
\hline-1.9946 & 199.72 & -1.9946 & 199.72 & -2.0 & 199.86 \\
\hline-0.24999 & 222.68 & -0.24999 & 222.68 & -0.25 & 222.68 \\
\hline-1.9963 & 298.44 & -1.9963 & 298.44 & -2.0 & 298.56 \\
\hline-0.24999 & 326.31 & -0.24999 & 326.31 & -0.25 & 326.13 \\
\hline-1.9973 & 416.90 & -1.9973 & 416.90 & -2.0 & 418.99 \\
\hline-0.25000 & 449.68 & -0.25000 & 449.68 & -0.25 & 449.68 \\
\hline-1.9979 & 555.08 & -1.9979 & 555.08 & -2.0 & 555.17 \\
\hline-0.25000 & 592.79 & -0.24999 & 592.79 & -0.25 & 592.79 \\
\hline-1.9983 & 713.00 & -1.9983 & 713.00 & -2.0 & 713.08 \\
\hline-0.25000 & 755.64 & -0.25004 & 755.64 & -0.25 & 755.64 \\
\hline-1.9989 & 890.67 & -1.9984 & 890.67 & -2.0 & 890.73 \\
\hline-0.25000 & 938.23 & -0.25003 & 938.23 & -0.25 & 938.23 \\
\hline
\end{tabular}

Table 2. Types I and III joints, C-F end conditions, with $p_{11}=2$, $p_{12}=0.5, q_{11}=q_{12}=0$.

For Table 5, we consider a type II joint with C-F end conditions. The purpose here is to investigate the behavior of the "undamped" branch, the contribution of $q_{21}$ and $q_{22}$ to the imaginary parts of the eigenfrequencies, and, of course, again to compare the numerical and asymptotic results.

Here, we let $p_{21}=p_{22}=1$. The first two columns give the numerical results, and the next two columns the asymptotic results for the case where $q_{21}=q_{22}=0$. We see here that the numerical real parts for the "undamped" branch are very small and, in most cases, are negative, as expected. For those that are not negative (the fifth, seventh and thirteenth eigenfrequencies), we assume that it is due to the numerical approximation. In addition, the match between the numerical and asymptotic results is again quite good, even as early as the second eigenfrequency. This can also be seen clearly in Figure 3, where we have plotted these results.

The last four columns are arranged as are the first four, but here we have let $q_{21}=0.5$ and $q_{22}=0.7$. We note that the effect of these values on the imaginary 


\begin{tabular}{|c|c|c|c|c|c|}
\hline \multicolumn{2}{|c|}{$\begin{array}{c}\text { type I } \\
\text { numerical }\end{array}$} & \multicolumn{2}{|c|}{$\begin{array}{c}\text { type III } \\
\text { numerical }\end{array}$} & \multicolumn{2}{|c|}{ WPM } \\
\hline $\operatorname{Re}$ & Im & $\operatorname{Re}$ & Im & $\operatorname{Re}$ & Im \\
\hline-0.41842 & 0.79717 & -0.41842 & 0.79717 & & \\
\hline-1.0353 & 5.3641 & -1.0353 & 5.3641 & -1.0 & 5.5517 \\
\hline-3.8189 & 17.042 & -3.8189 & 17.042 & -8.0 & 22.207 \\
\hline-0.99732 & 30.143 & -0.99732 & 30.143 & -1.0 & 30.226 \\
\hline-6.6452 & 57.777 & -6.6452 & 57.777 & -8.0 & 61.685 \\
\hline-0.99849 & 74.584 & -0.99849 & 74.584 & -1.0 & 74.639 \\
\hline-7.3547 & 118.07 & -7.3547 & 118.07 & -8.0 & 120.90 \\
\hline-0.99909 & 138.75 & -0.99909 & 138.75 & -1.0 & 138.79 \\
\hline-7.6154 & 197.65 & -7.6154 & 197.65 & -8.0 & 199.86 \\
\hline-0.99940 & 222.65 & -0.99940 & 222.65 & -1.0 & 222.68 \\
\hline-7.7423 & 296.75 & -7.7423 & 296.75 & -8.0 & 298.56 \\
\hline-0.99957 & 326.29 & -0.99957 & 326.29 & -1.0 & 326.13 \\
\hline-7.8144 & 415.45 & -7.8144 & 415.46 & -8.0 & 418.99 \\
\hline-0.99968 & 449.66 & -0.99969 & 449.66 & -1.0 & 449.68 \\
\hline-7.8598 & 553.83 & -7.8595 & 553.83 & -8.0 & 555.17 \\
\hline-0.99977 & 592.77 & -0.99980 & 592.77 & -1.0 & 592.79 \\
\hline-7.8901 & 711.90 & -7.8905 & 711.91 & -8.0 & 713.08 \\
\hline-0.99976 & 755.62 & -0.99947 & 755.62 & -1.0 & 755.64 \\
\hline-7.9105 & 889.67 & -7.9140 & 889.68 & -8.0 & 890.73 \\
\hline-0.99981 & 938.20 & -0.99924 & 938.22 & -1.0 & 938.23 \\
\hline
\end{tabular}

Table 3. Types I and III joints, C-F end conditions, with $p_{11}=0.5$, $p_{12}=2, q_{11}=q_{12}=0$.

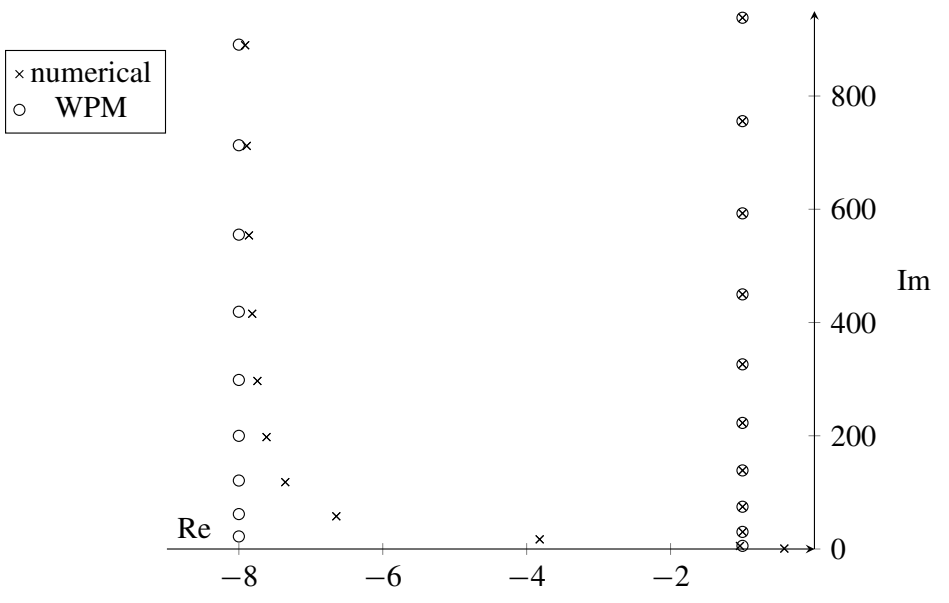

Figure 1. Plot of the vibration frequencies from Table 3. 


\begin{tabular}{|cc|cc|lc|}
\hline \multicolumn{2}{|c|}{$\begin{array}{c}\text { type I } \\
\text { numerical }\end{array}$} & \multicolumn{2}{c|}{$\begin{array}{c}\text { type III } \\
\text { numerical }\end{array}$} & \multicolumn{2}{c|}{ WPM } \\
\hline $\operatorname{Re}$ & $\mathrm{Im}$ & $\mathrm{Re}$ & $\mathrm{Im}$ & $\mathrm{Re}$ & $\mathrm{Im}$ \\
\hline-0.45378 & 0.76895 & -0.45378 & 0.76895 & & \\
-0.95917 & 5.2515 & -0.95917 & 5.2515 & -1.35 & 5.5517 \\
-3.6112 & 17.067 & -3.6112 & 17.067 & -8.0 & 22.207 \\
-1.0664 & 29.951 & -1.0664 & 29.951 & -1.35 & 30.226 \\
-6.5928 & 57.645 & -6.5928 & 57.645 & -8.0 & 61.685 \\
-1.1599 & 74.377 & -1.1599 & 74.377 & -1.35 & 74.639 \\
-7.3698 & 117.99 & -7.3698 & 117.99 & -8.0 & 120.90 \\
-1.2226 & 138.56 & -1.2226 & 138.56 & -1.35 & 138.79 \\
-7.6396 & 197.61 & -7.6396 & 197.61 & -8.0 & 199.86 \\
-1.2611 & 222.48 & -1.2611 & 222.48 & -1.35 & 222.68 \\
-7.7645 & 296.72 & -7.7645 & 296.72 & -8.0 & 298.56 \\
-1.2853 & 326.14 & -1.2853 & 325.14 & -1.35 & 326.13 \\
-7.8331 & 415.44 & -7.8331 & 415.44 & -8.0 & 418.99 \\
-1.3012 & 449.53 & -1.3012 & 449.53 & -1.35 & 449.68 \\
-7.8751 & 553.82 & -7.8751 & 553.82 & -8.0 & 555.17 \\
-1.3119 & 592.65 & -1.3120 & 592.65 & -1.35 & 592.79 \\
-7.9026 & 711.89 & -7.9028 & 711.89 & -8.0 & 713.08 \\
-1.3197 & 755.51 & -1.3196 & 755.52 & -1.35 & 755.64 \\
-7.9225 & 889.67 & -7.9222 & 889.67 & -8.0 & 890.73 \\
-1.3253 & 938.12 & -1.3251 & 938.11 & -1.35 & 938.23 \\
\hline
\end{tabular}

Table 4. Types I and III joints, C-F end conditions, with $p_{11}=$ $p_{12}=1, q_{11}=0.5, q_{12}=0.7$.

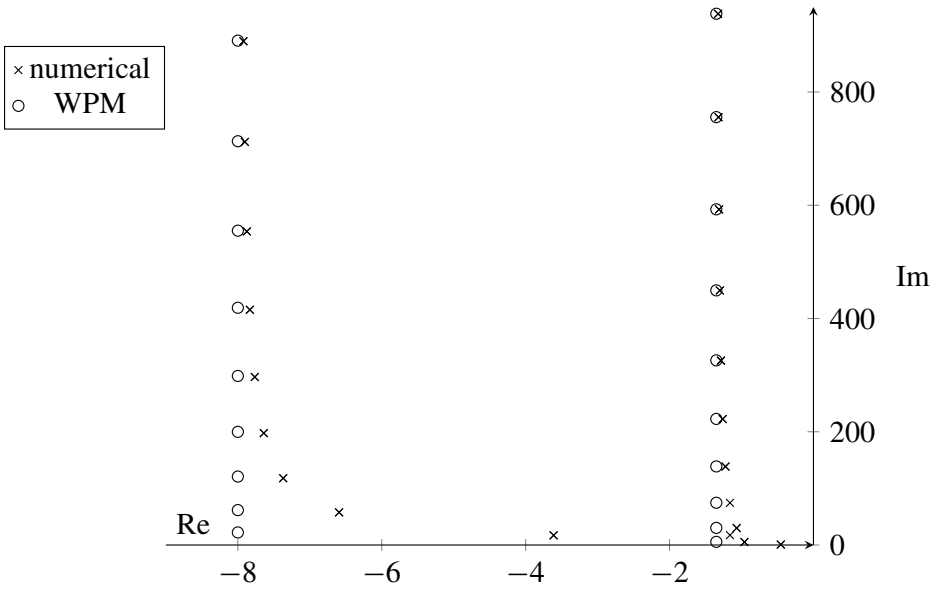

Figure 2. Plot of the vibration frequencies from Table 4. 


\begin{tabular}{|cc|rcc|lc|rc|}
\hline \multicolumn{7}{|c|}{ type II joint } \\
\hline \multicolumn{7}{|c|}{$q_{11}=q_{12}=0$} & & \multicolumn{3}{|c|}{$q_{11}=0.5, q_{12}=0.7$} \\
\hline \multicolumn{2}{|c|}{ numerical } & \multicolumn{2}{c|}{ WPM } & \multicolumn{2}{|c|}{ numerical } & \multicolumn{2}{c|}{ WPM } \\
Re & Im & Re & Im & Re & Im & Re & Im \\
\hline-0.21945 & 0.82672 & 0.0 & 0.61685 & -0.16897 & 0.72184 & 0.0 & 0.61685 \\
-1.0236 & 5.5617 & -1.0 & 5.5517 & -0.95445 & 6.1571 & -1.0 & 6.1577 \\
$-7.6 \cdot 10^{-4}$ & 15.424 & 0.0 & 15.421 & $-6.6 \cdot 10^{-4}$ & 15.424 & 0.0 & 15.421 \\
-1.0025 & 30.234 & -1.0 & 30.226 & -0.98966 & 30.834 & -1.0 & 30.826 \\
$1.4 \cdot 10^{-6}$ & 49.964 & 0.0 & 49.965 & $-1.3 \cdot 10^{-6}$ & 49.965 & 0.0 & 49.965 \\
-1.0011 & 74.642 & -1.0 & 74.639 & -0.99584 & 75.242 & -1.0 & 75.239 \\
$3.4 \cdot 10^{-10}$ & 104.25 & 0.0 & 104.25 & $1.1 \cdot 10^{-9}$ & 104.25 & 0.0 & 104.25 \\
-1.0006 & 138.70 & -1.0 & 138.79 & -0.99777 & 139.39 & -1.0 & 139.39 \\
$-1.3 \cdot 10^{-8}$ & 178.27 & 0.0 & 178.27 & $-1.1 \cdot 10^{-8}$ & 178.27 & 0.0 & 178.27 \\
-1.0004 & 222.68 & -1.0 & 222.68 & -0.99861 & 223.28 & -1.0 & 223.28 \\
$-9.5 \cdot 10^{-8}$ & 272.03 & 0.0 & 272.03 & $-7.5 \cdot 10^{-8}$ & 272.03 & 0.0 & 272.03 \\
-1.0003 & 326.31 & -1.0 & 326.31 & -0.99905 & 326.91 & -1.0 & 326.91 \\
$2.2 \cdot 10^{-8}$ & 385.53 & 0.0 & 385.53 & $3.8 \cdot 10^{-7}$ & 385.53 & 0.0 & 385.53 \\
-1.0002 & 449.68 & -1.0 & 449.68 & -0.99930 & 450.28 & -1.0 & 450.28 \\
$-5.3 \cdot 10^{-8}$ & 518.77 & 0.0 & 518.77 & $-5.4 \cdot 10^{-7}$ & 518.77 & 0.0 & 518.77 \\
-1.0001 & 592.79 & -1.0 & 592.79 & -0.99947 & 593.39 & -1.0 & 593.39 \\
$-8.1 \cdot 10^{-6}$ & 671.75 & 0.0 & 671.75 & $-7.6 \cdot 10^{-6}$ & 671.75 & 0.0 & 671.75 \\
-1.0002 & 755.64 & -1.0 & 755.64 & -0.99970 & 756.24 & -1.0 & 756.24 \\
$-8.5 \cdot 10^{-6}$ & 844.47 & 0.0 & 844.47 & $-2.2 \cdot 10^{-5}$ & 844.48 & 0.0 & 844.47 \\
-1.0002 & 938.23 & -1.0 & 938.23 & -0.99972 & 938.84 & -1.0 & 938.83 \\
\hline
\end{tabular}

Table 5. Type II joint, C-F end conditions, with $p_{11}=p_{12}=1$, $q_{11}=q_{12}=0$, and $p_{11}=p_{12}=1, q_{11}=0.5, q_{12}=0.7$.

parts of the eigenfrequencies of the "damped" branch should be

$$
\frac{q_{21}+q_{22}}{2}=0.6
$$

and, indeed, this is what we see in the numerical results. Here, again, and in Figure 4, we see a strong match between the numerical and asymptotic results.

Table 6 is arranged exactly as Table 5, but here we consider, instead, a type IV joint, with $p_{41}=p_{42}=1$. As before, $q_{41}=q_{42}=0$ for the first four columns, while $q_{41}=0.5$ and $q_{42}=0.7$ for the last four. Once more, we provide the first twenty eigenfrequencies. For the $q_{41}=q_{42}=0$ results, the asymptotic results occur in pairs with equal imaginary parts, and we can see from the table and from Figure 5, where these data are plotted, that the numerical results are approaching the same behavior asymptotically. For the case $q_{41}=0.5, q_{42}=0.7$, we again see the effect of nonzero 


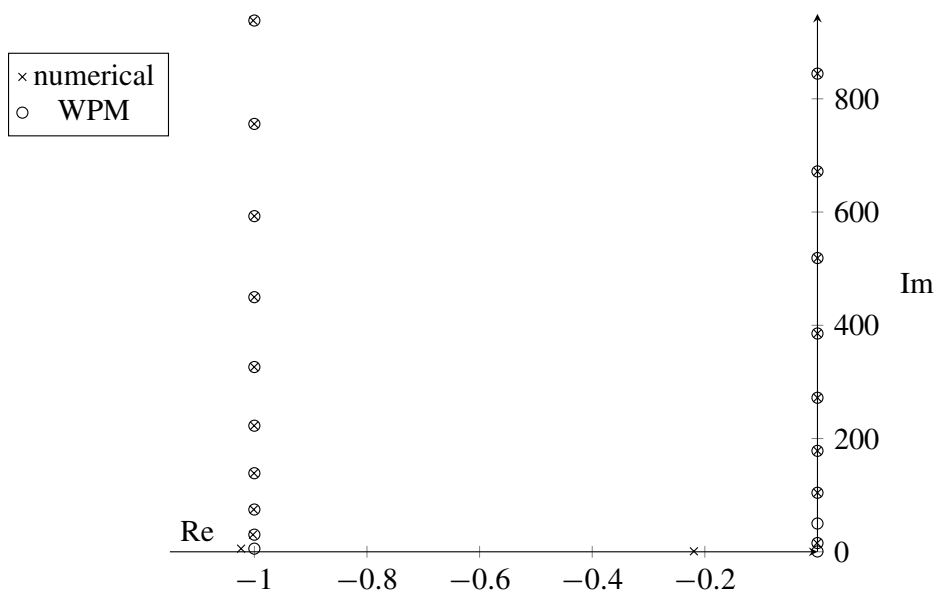

Figure 3. Plot of the vibration frequencies from Table 5 for the case $q_{11}=q_{12}=0$.

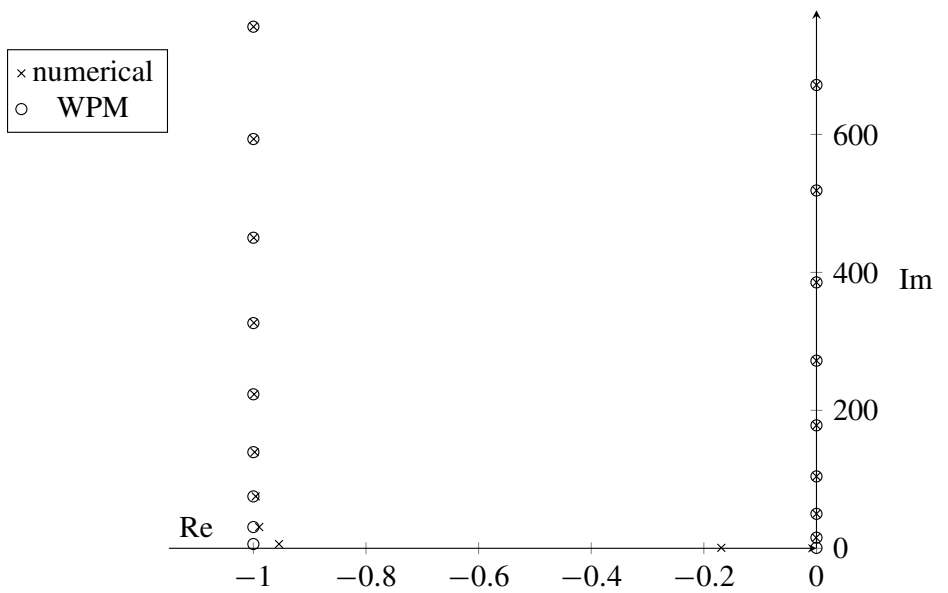

Figure 4. Plot of the vibration frequencies from Table 5 for the case $q_{11}=0.5, q_{12}=0.7$.

$q$-values on the imaginary part of the "damped" branch. Here, the effect is

$$
\frac{q_{41}+q_{42}}{p_{41} p_{42}+q_{41} q_{42}}=1.7778 .
$$

We plot these results in Figure 6, where, although it is difficult to see the effects of the nonzero $q$-values, we can see, again, a very good match between the asymptotic and numerical results.

We realize that the damping parameters we have used may not be physically realistic. Indeed, in other work, we have seen that, for realistic data, the convergence 


\begin{tabular}{|c|c|c|c|c|c|c|c|}
\hline \multicolumn{8}{|c|}{ type IV joint } \\
\hline \multicolumn{4}{|c|}{$q_{41}=q_{42}=0$} & \multicolumn{4}{|c|}{$q_{41}=0.5, q_{42}=0.7$} \\
\hline \multicolumn{2}{|c|}{ numerical } & \multicolumn{2}{|c|}{ WPM } & \multicolumn{2}{|c|}{ numerical } & \multicolumn{2}{|c|}{ WPM } \\
\hline $\operatorname{Re}$ & $\operatorname{Im}$ & $\operatorname{Re}$ & Im & $\operatorname{Re}$ & $\operatorname{Im}$ & $\operatorname{Re}$ & $\operatorname{Im}$ \\
\hline $3.3 \cdot 10^{-16}$ & 0.0000 & & & $7.8 \cdot 10^{-16}$ & 0.0000 & & \\
\hline-0.46155 & 0.53410 & & & -0.26096 & 0.45158 & & \\
\hline$-4.2 \cdot 10^{-2}$ & 5.5592 & 0.0 & 5.5517 & $-2.3 \cdot 10^{-2}$ & 5.5606 & 0.0 & 5.5517 \\
\hline-4.0964 & 6.6697 & -4.0 & 5.5517 & -2.3443 & 7.6742 & -2.96 & 7.3295 \\
\hline$-1.2 \cdot 10^{-4}$ & 30.226 & 0.0 & 30.226 & $-7.0 \cdot 10^{-5}$ & 30.226 & 0.0 & 30.226 \\
\hline-4.1652 & 30.395 & -4.0 & 30.226 & -2.8528 & 32.136 & -2.96 & 32.004 \\
\hline$-1.2 \cdot 10^{-4}$ & 74.639 & 0.0 & 74.639 & $-1.5 \cdot 10^{-7}$ & 74.639 & 0.0 & 74.639 \\
\hline-4.0704 & 74.698 & -4.0 & 74.639 & -2.9217 & 76.474 & -2.96 & 76.417 \\
\hline$-2.1 \cdot 10^{-10}$ & 138.79 & 0.0 & 138.79 & $2.3 \cdot 10^{-9}$ & 138.79 & 0.0 & 138.79 \\
\hline-4.0382 & 138.82 & -4.0 & 138.79 & -2.9415 & 140.60 & -2.96 & 140.57 \\
\hline$-1.4 \cdot 10^{-8}$ & 222.68 & 0.0 & 222.68 & $-2.4 \cdot 10^{-10}$ & 222.68 & 0.0 & 222.68 \\
\hline-4.0239 & 222.70 & -4.0 & 222.68 & -2.9498 & 224.48 & -2.96 & 224.46 \\
\hline$-3.5 \cdot 10^{-8}$ & 326.31 & 0.0 & 326.31 & $-5.0 \cdot 10^{-8}$ & 326.31 & 0.0 & 326.31 \\
\hline-4.0163 & 326.33 & -4.0 & 326.31 & -2.9540 & 328.10 & -2.96 & 328.09 \\
\hline$-8.7 \cdot 10^{-8}$ & 449.68 & 0.0 & 449.68 & $-2.7 \cdot 10^{-7}$ & 449.68 & 0.0 & 449.68 \\
\hline-4.0118 & 449.69 & -4.0 & 449.68 & -2.9565 & 451.47 & -2.96 & 451.46 \\
\hline$-3.2 \cdot 10^{-7}$ & 592.79 & 0.0 & 592.79 & $1.2 \cdot 10^{-7}$ & 592.79 & 0.0 & 592.79 \\
\hline-4.0090 & 592.80 & -4.0 & 592.79 & -2.9581 & 594.58 & -2.96 & 594.57 \\
\hline $1.8 \cdot 10^{-6}$ & 755.64 & 0.0 & 755.64 & $3.6 \cdot 10^{-6}$ & 755.64 & 0.0 & 755.64 \\
\hline-4.0071 & 755.65 & -4.0 & 755.64 & -2.9592 & 757.42 & -2.96 & 757.42 \\
\hline
\end{tabular}

Table 6. Type IV joint, C-F end conditions, with $p_{11}=p_{12}=1$, $q_{11}=q_{12}=0$, and $p_{11}=p_{12}=1, q_{11}=0.5, q_{12}=0.7$.

of the numerical to the asymptotic results sometimes takes much longer. However, we have not been able to find realistic parameters in the literature. In particular, in the two papers which give experimental results [Chen et al. 1988; 1989], the physical parameters have not been determined, and the comparison with the asymptotic results is based instead on a very clever use of the patterns that result from looking at various differences between the eigenfrequencies.

Finally, we should mention that, in order to utilize the wave propagation method in its current form, it is necessary that the possible wave speeds are the same along each beam, thus the assumption here and in the references that each of the physical parameters $m, E$, and $I$ is the same for each beam. We can generalize a bit, given that the wave speeds actually depend only on the ratio $E I / m$, so we need only have the ratio be the same for each beam. Once this condition is not met, however, the problem becomes far more difficult — indeed, we have found nothing in the literature regarding an asymptotic analysis of this problem. 


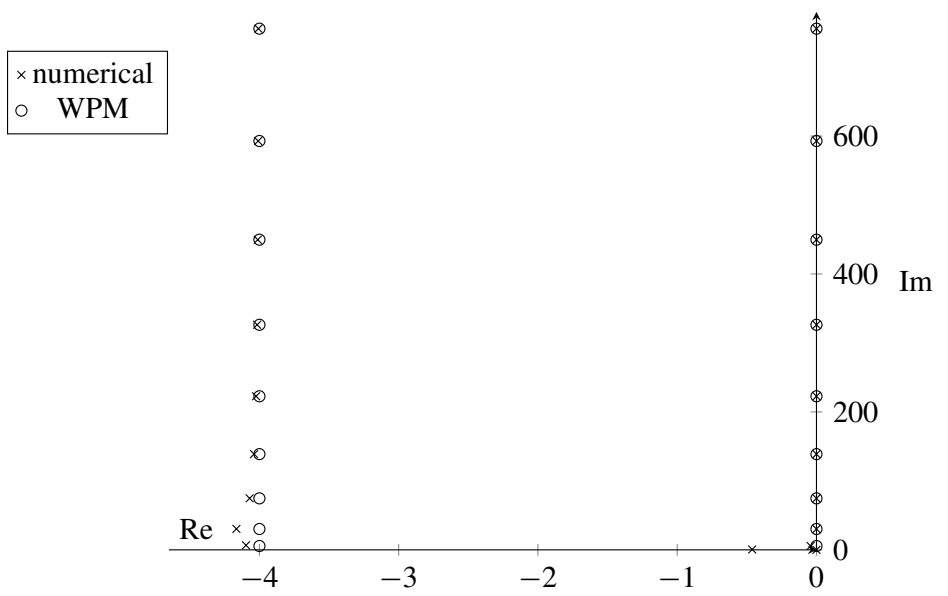

Figure 5. Plot of the vibration frequencies from Table 6 for the case $q_{41}=q_{42}=0$.

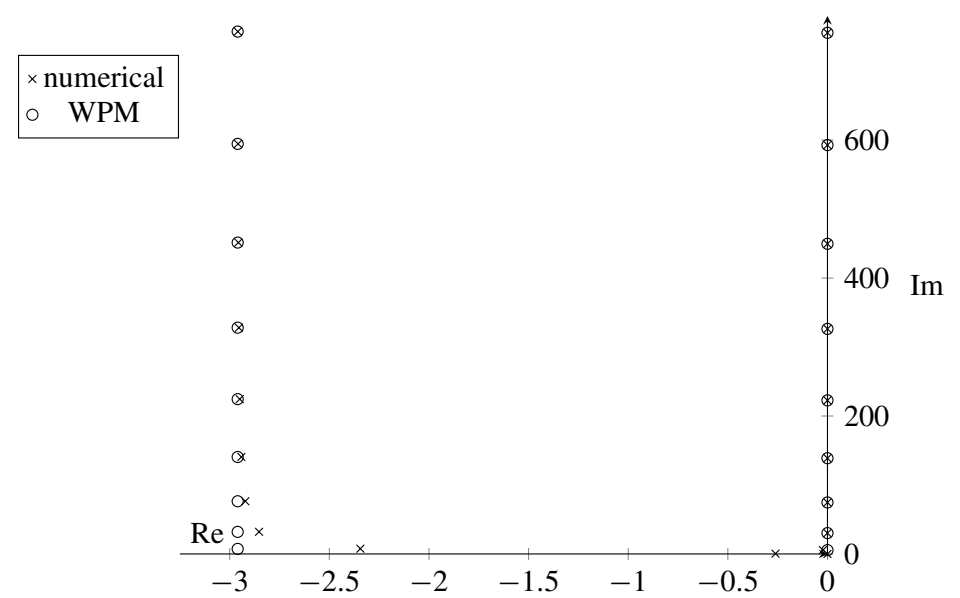

Figure 6. Plot of the vibration frequencies from Table 6 for the case $q_{41}=0.5, q_{42}=0.7$.

\section{References}

[Chen and Zhou 1990] G. Chen and J. Zhou, "The wave propagation method for the analysis of boundary stabilization in vibrating structures", SIAM J. Appl. Math. 50:5 (1990), 1254-1283. MR $\mathrm{Zbl}$

[Chen et al. 1987] G. Chen, M. C. Delfour, A. M. Krall, and G. Payre, "Modeling, stabilization and control of serially connected beams", SIAM J. Control Optim. 25:3 (1987), 526-546. MR Zbl

[Chen et al. 1988] G. Chen, S. G. Krantz, D. L. Russell, C. E. Wayne, H. H. West, and J. Zhou, "Modelling, analysis and testing of dissipative beam joints - experiments and data smoothing", Math. Comput. Modelling 11 (1988), 1011-1016. MR 
[Chen et al. 1989] G. Chen, S. G. Krantz, D. L. Russell, C. E. Wayne, H. H. West, and M. P. Coleman, "Analysis, designs, and behavior of dissipative joints for coupled beams", SIAM J. Appl. Math. 49:6 (1989), 1665-1693. MR

[Gottlieb and Orszag 1977] D. Gottlieb and S. A. Orszag, Numerical analysis of spectral methods: theory and applications, CBMS-NSF Regional Conference Series in Applied Mathematics 26, SIAM, Philadelphia, PA, 1977. MR Zbl

[Keller and Rubinow 1960] J. B. Keller and S. I. Rubinow, "Asymptotic solution of eigenvalue problems", Ann. Phys. 9:1 (1960), 24-75. Zbl

[Krantz and Paulsen 1991] S. G. Krantz and W. H. Paulsen, "Asymptotic eigenfrequency distributions for the $N$-beam Euler-Bernoulli coupled beam equation with dissipative joints", J. Symbolic Comput. 11:4 (1991), 369-418. MR Zbl

[Pilkey 1969] W. D. Pilkey, "Analysis for the response of structural members", Research Institute Project J6094, Illinois Institute of Technology, 1969.

Received: 2015-11-07 Revised: 2016-01-21 Accepted: 2016-04-01

christopher.abriola@gmail.com Department of Mathematics and Statistics, University of New Hampshire, Durham, NH 03824, United States

mcoleman@fairfield.edu Department of Mathematics and Computer Science, Fairfield University, Fairfield, CT 06824, United States

aglika.darakchieva@uconn.edu Department of Mathematics, University of Connecticut, Storrs, CT 06269, United States

tylermwales@gmail.com

Department of Mathematics, Louisiana State University, Baton Rouge, LA 70803, United States 



\title{
involve
}

\author{
msp.org/involve
}

INVOLVE YOUR STUDENTS IN RESEARCH

Involve showcases and encourages high-quality mathematical research involving students from all academic levels. The editorial board consists of mathematical scientists committed to nurturing student participation in research. Bridging the gap between the extremes of purely undergraduate research journals and mainstream research journals, Involve provides a venue to mathematicians wishing to encourage the creative involvement of students.

\author{
MANAGING EDITOR \\ Kenneth S. Berenhaut Wake Forest University, USA
}

$\begin{aligned} & \text { Colin Adams } \text { Williams College, USA } \\ & \text { John V. Baxley } \text { Wake Forest University, NC, USA } \\ & \text { Arthur T. Benjamin } \text { Harvey Mudd College, USA } \\ & \text { Martin Bohner } \text { Missouri U of Science and Technology, USA } \\ & \text { Nigel Boston } \text { University of Wisconsin, USA } \\ & \text { Amarjit S. Budhiraja } \text { U of North Carolina, Chapel Hill, USA } \\ & \text { Pietro Cerone } \text { La Trobe University, Australia } \\ & \text { Scott Chapman } \text { Sam Houston State University, USA } \\ & \text { Joshua N. Cooper } \text { University of South Carolina, USA } \\ & \text { Jem N. Corcoran } \text { University of Colorado, USA } \\ & \text { Toka Diagana } \text { Howard University, USA } \\ & \text { Michael Dorff } \text { Brigham Young University, USA } \\ & \text { Sever S. Dragomir } \text { Victoria University, Australia } \\ & \text { Behrouz Emamizadeh } \text { The Petroleum Institute, UAE } \\ & \text { Joel Foisy } \text { SUNY Potsdam, USA } \\ & \text { Errin W. Fulp } \text { Wake Forest University, USA } \\ & \text { Joseph Gallian } \text { University of Minnesota Duluth, USA } \\ & \text { Stephan R. Garcia } \text { Pomona College, USA } \\ & \text { Anant Godbole } \text { East Tennessee State University, USA } \\ & \text { Ron Gould } \text { Emory University, USA } \\ & \text { Andrew Granville } \text { Université Montréal, Canada } \\ & \text { Jerrold Griggs } \text { University of South Carolina, USA } \\ & \text { Sat Gupta } \text { U of North Carolina, Greensboro, USA } \\ & \text { Jim Haglund } \text { University of Pennsylvania, USA } \\ & \text { Johnny Henderson } \text { Baylor University, USA } \\ & \text { Jim Hoste } \text { Pitzer College, USA } \\ & \text { Charles R. Johnson } \text { College of William and Mary, USA } \\ & \text { K. B. Kulasekera } \text { Clemson University, USA } \\ & \text { Gerry Ladas } \text { University of Rhode Island, USA } \\ & \text { Prairie View A\&M University, USA } \\ & \text { Jianko }\end{aligned}$

Colin Adams

Martin Bohne

Scott Chapman

Michael Dorff

Foisy
Suzanne Lenhart

Chi-Kwong Li

Robert B. Lund

Gaven J. Martin

Mary Meyer

Emil Minchev

Frank Morgan

Mohammad Sal Moslehian

Zuhair Nashed

Ken Ono

Timothy E. O'Brien

Joseph O'Rourke

Yuval Peres

Y.-F. S. Pétermann

Robert J. Plemmons

Carl B. Pomerance

Vadim Ponomarenko

Bjorn Poonen

James Propp

Józeph H. Przytycki

Richard Rebarber

Robert W. Robinson

Filip Saidak

James A. Sellers

Andrew J. Sterge

Ann Trenk

Ravi Vakil

Antonia Vecchio

Ram U. Verma

John C. Wierman

Michael E. Zieve
University of Tennessee, USA

College of William and Mary, USA

Clemson University, USA

Massey University, New Zealand

Colorado State University, USA

Ruse, Bulgaria

Williams College, USA

Ferdowsi University of Mashhad, Iran

University of Central Florida, USA

Emory University, USA

Loyola University Chicago, USA

Smith College, USA

Microsoft Research, USA

Université de Genève, Switzerland

Wake Forest University, USA

Dartmouth College, USA

San Diego State University, USA

UC Berkeley, USA

U Mass Lowell, USA

George Washington University, USA

University of Nebraska, USA

University of Georgia, USA

U of North Carolina, Greensboro, USA

Penn State University, USA

Honorary Editor

Wellesley College, USA

Stanford University, USA

Consiglio Nazionale delle Ricerche, Italy

University of Toledo, USA

Johns Hopkins University, USA

University of Michigan, USA

PRODUCTION

Silvio Levy, Scientific Editor

Cover: Alex Scorpan

See inside back cover or msp.org/involve for submission instructions. The subscription price for 2017 is US $\$ 175 /$ year for the electronic version, and \$235/year ( $\$ 35$, if shipping outside the US) for print and electronic. Subscriptions, requests for back issues from the last three years and changes of subscribers address should be sent to MSP.

Involve (ISSN 1944-4184 electronic, 1944-4176 printed) at Mathematical Sciences Publishers, 798 Evans Hall \#3840, c/o University of California, Berkeley, CA 94720-3840, is published continuously online. Periodical rate postage paid at Berkeley, CA 94704, and additional mailing offices.

Involve peer review and production are managed by EditFLOW ${ }^{\circledR}$ from Mathematical Sciences Publishers.

\section{PUBLISHED BY}

mathematical sciences publishers

nonprofit scientific publishing

http://msp.org/

(C) 2017 Mathematical Sciences Publishers 


\section{involve 2017 vol. $10 \quad$ no. 3}

Dynamics of vertical real rhombic Weierstrass elliptic functions

LORELEI KOSS AND KATIE ROY

Pattern avoidance in double lists

Charles Cratty, Samuel Erickson, Frehiwet Negassi and Lara

PUDWELL

On a randomly accelerated particle

MiCHELlE NUNO AND JUHI JANG

Reeb dynamics of the link of the $A_{n}$ singularity

Leonardo Abbrescia, Irit HuQ-Kuruvilla, Jo Nelson and NawaZ

SULTANI

The vibration spectrum of two Euler-Bernoulli beams coupled via a dissipative joint

Chris Abriola, Matthew P. Coleman, Aglika Darakchieva And TYLER WALES

Loxodromes on hypersurfaces of revolution

JACOB BLACKWOOD, ADAM DUKEHART AND MOHAMMAD JAVAHERI

Existence of positive solutions for an approximation of stationary mean-field games

Nojood Almayouf, Elena Bachini, Andreia Chapouto, Rita

FERreira, Diogo Gomes, DANIEla Jordẽo, DaVid EVANGElista

Junior, AVEtik Karagulyan, Juan Monasterio, LeVon

Nurbekyan, Giorgia Pagliar, Marco Piccirilli, Sagar Pratapsi,

Mariana Prazeres, JoÃo Reis, ANdré Rodrigues, Orlando

Romero, Maria Sargsyan, Tommaso Seneci, Chuliang Song,

Kengo Terai, Ryota Tomisaki, Hector Velasco-Perez, VARdan

VOSKANYAN AND XIANJIN YANG

Discrete dynamics of contractions on graphs

Olena OSTAPYUK AND MARK RONNENBERG

Tiling annular regions with skew and T-tetrominoes

Amanda Bright, Gregory J. Clark, Charles Dunn, Kyle Evitts,

Michael P. Hitchman, BRian KeATING AND BRIAN WHETTER

A bijective proof of a $q$-analogue of the sum of cubes using overpartitions

JACOB FORSTER, KRISTINA GARRETT, LUKE JACOBSEN AND ADAM

WOOD

Ulrich partitions for two-step flag varieties

IZZET COSKUN AND LUKE JASKOWIAK 